Article

\title{
Spike Activator 1, Encoding a bHLH, Mediates Axillary Bud Development and Spike Initiation in Phalaenopsis aphrodite
}

\author{
Yi-Jyun Lin ${ }^{1,+}$, Min-Jeng Li ${ }^{1,+}$, Hung-Chien Hsing ${ }^{1}$, Tien-Kuan Chen ${ }^{1}$, Ting-Ting Yang ${ }^{1}$ and \\ Swee-Suak Ko ${ }^{1,2, *(D)}$ \\ 1 Academia Sinica Biotechnology Center in Southern Taiwan, Tainan 741, \\ Taiwan; hbabyi@gate.sinica.edu.tw (Y.-J.L.); lmz8332@yahoo.com.tw (M.-J.L.); \\ sanny618@gmail.com (H.-C.H.); s4life2010@gmail.com (T.-K.C.); tty0318@gmail.com (T.-T.Y.) \\ 2 Agricultural Biotechnology Research Center, Academia Sinica, Taipei 115, Taiwan \\ * Correspondence: sweesuak@gate.sinica.edu.tw; Tel.: +886-6-5056630 (ext. 206); Fax: +886-6-5056631 \\ (ext. 206) \\ $\dagger$ These authors contributed equally to this work.
}

Received: 20 September 2019; Accepted: 28 October 2019; Published: 30 October 2019

\begin{abstract}
Double-spikes Phalaenopsis orchids have greater market value than those with single-spike. In this study, a gene designated as Spike Activator 1 (SPK1), which encodes a basic helix-loop-helix $(\mathrm{bHLH})$ transcription factor, was isolated and characterized from Phalaenopsis aphrodite (moth orchid). SPK1 was highly expressed in the meristematic tissues. In the axillary bud, SPK1 was highly upregulated by a moderately low temperature of $20^{\circ} \mathrm{C}$ but downregulated by a spike inhibition temperature of $30^{\circ} \mathrm{C}$. SPK1 protein is localized in the nucleus. Another bHLH, bHLH35, which is also highly expressed in young tissues in the same way as SPK1 was also identified. In contrast to SPK1, bHLH35 transcripts are downregulated at $20^{\circ} \mathrm{C}$ but upregulated at $30^{\circ} \mathrm{C}$. Bimolecular florescence complementation assay and yeast two-hybrid assays indicated that SPK1 interacts with bHLH35 and forms a heterodimer. Virus-induced gene silencing (VIGS) showed that 7 out of 15 vector control plants produced double spikes but that only 1 out of 15 VIGS-spk1 plants produced double spikes. RT-qPCR results indicated that VIGS-spk1 downregulated gene expression levels of SPK1, $F T, C Y C B$, and EXPA8. Overall, we propose that SPK1 plays an essential role in early axillary bud development and spike initiation of $P$. aphrodite.
\end{abstract}

Keywords: moth orchid; axillary bud; spike induction; spiking; gene regulation; bHLH; FT; expansin

\section{Introduction}

Phalaenopsis aphrodite (moth orchid) is one of the most important export ornamental plants in the world. The potted orchid and cut-flower orchid market is flourishing, and it is a growing industry. Floral spikes of Phalaenopsis orchids are initiated from axillary buds at the leaf base. After a period of moderately low-temperature induction for one and a half months, axillary buds enlarge, break dormancy, and protrude from the leaf base to develop into young floral spikes.

Temperature is a critical factor in spike induction of Phalaenopsis orchids. Some researchers recommend a day/night temperature fluctuation of $25^{\circ} \mathrm{C} / 20^{\circ} \mathrm{C}$ or $20^{\circ} \mathrm{C} / 15^{\circ} \mathrm{C}$ [1]. However, some indicated that Phalaenopsis orchid can initiate spikes at constant 14 to $23^{\circ} \mathrm{C}$ or fluctuating day/night temperatures of $20^{\circ} \mathrm{C} / 14^{\circ} \mathrm{C}$ or $23^{\circ} \mathrm{C} / 17^{\circ} \mathrm{C}$. It has also been found that orchids produced more spikes under constant $14{ }^{\circ} \mathrm{C}$ and $17{ }^{\circ} \mathrm{C}$. Therefore, researchers concluded that day/night temperature fluctuation is not necessary for spike initiation [2]. Conversely, Phal. orchid spiking was significantly inhibited when it was grown at a temperature higher than $28^{\circ} \mathrm{C}[3,4]$. In addition to temperature, low light resulted in 
low photosynthesis rate and delayed spiking in moth orchid [5]. Once orchid spiking was initiated, the plants took 10 to 15 weeks to flower at 20 to $23^{\circ} \mathrm{C}[2,6]$.

FLOWERING LOCUS T (FT) is a flowering marker in many plant species. In the shoot apical meristem (SAM), FT interacts with FLOWERING LOCUS D (FD) to promote flowering and the activation of floral meristem identity genes. Therefore, FT may represent a long-distance signal in flowering [7]. Some genes controlling flowering in orchid have been reported recently. Phalaenopsis orchid FT interacting with FD might regulate downstream genes such as AP1, SOC1, and Leafy [8]. FD and FT are interdependent partners through protein interaction and act at the shoot apex to promote floral transition and to initiate floral development through transcriptional activation of a floral meristem identity gene, APETALA1 (AP1). FT protein is transported to the SAM via the phloem [9].

Cell-cycle control is important for plant growth and development. Cyclins activate the kinase activity of the cyclin-dependent kinases (CDKs) and control timely cell-cycle processes [10]. CYCB gene family members are preferentially accumulated during S, G2, and M phases and are often used as markers for dividing cells [11]. Phal. orchid CYCB1;1 is highly expressed in the developing embryos and in the meristem tissues of the protocorm [10]. Also, CYCB1;1 is expressed more abundantly in the 3rd axillary bud than the 2nd axillary bud, as revealed by In Situ Hybridization (ISH) [12]. Study of the relationship between endodormancy, FT, and cell cycle genes indicated that FT plays a key role in regulating cell-cycle genes transcriptionally [13].

Expansins are classified by sequence-based phylogeny into two major families named EXPA ( $\alpha$-expansins) and EXPB ( $\beta$-expansins) [14]. Expansins are cell-wall-loosening proteins that mediate acid-induced growth by catalyzing loosening of plant cell walls [15]. During growth, plant cells secrete expansins to loosen wall polysaccharides and to permit cell enlargement [16].

MYB is the largest, and basic helix-loop-helix (bHLH) is the second largest gene family. The MYB and bHLH families also interact with a number of other regulatory proteins, forming complexes that either activate or repress the expression of sets of target genes [17]. bHLH transcription factors (TFs) are involved in numerous biological processes in plants including responses to cold, light, and hormones; epidermal cell fate determination; and development of roots and flowers [18-26]. LAX PANICLE1 Protein (LAX1), a bHLH, is required for axillary meristem formation [27]. A bHLH complex of LHW-T5L1 activates vascular cell division via cytokinin action in the apical meristem of the root [28].

Little work has been done to address the gene regulatory pathways of axillary bud and spike development in orchid. To understand the physiological, cellular, and molecular processes of floral spike initiation in moth orchid, in this study, we carried out extensive experiments and isolated a novel bHLH, Spike Activator 1 (SPK1), which is highly expressed in the meristematic tissues of orchid and upregulated by moderately low temperature for spiking. SPK1 protein can form a homodimer and heterodimer with bHLH35. Virus-induced gene silencing (VIGS) experiment demonstrated that SPK1 is an important regulator mediating axillary bud development, spike initiation, and reproductive organ development in Phal. orchid.

\section{Results}

\subsection{Morphology of Axillary Bud Development after Spike Induction of Phal. Orchid}

Monopodial Phal. orchid has an upright main stem with several leaves growing in the alternate leaf positions. The axillary bud is a small organ embedded at the leaf base (Figure 1a). After axillary bud maturation and breaking dormancy, floral spikes will initiate and protrude from the leaf base. When a young spike ( $>2 \mathrm{~cm}$ in length) is observed, the spike development stage is defined as "spiking". The process of moderately low-temperature treatment to induce spiking is called "spike induction". Young spikes will then elongate to form a flower stalk and to develop flower buds, and blooming takes another 3 to 4 months after spiking (Figure 1b). Phal. orchid spiking is temperature and genetic-factor dependent [4]. In this study, we used commercial big white orchid cultivar "N2K01" mature $3.5^{\prime \prime}$ potted plants and compared spiking and non-spiking temperatures of $20^{\circ} \mathrm{C}$ and $30^{\circ} \mathrm{C}$, 
respectively. After treatment for 2 months at $20^{\circ} \mathrm{C}$, all plants can produce one to two young spikes but absolutely no spiking was observed after $30^{\circ} \mathrm{C}$ treatment (Figure 1c). Hence, we confirmed spike induction at $20^{\circ} \mathrm{C}$ is appropriate for this cultivar.

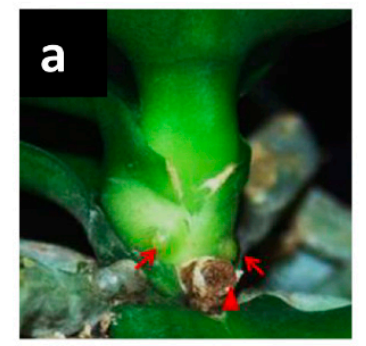

d
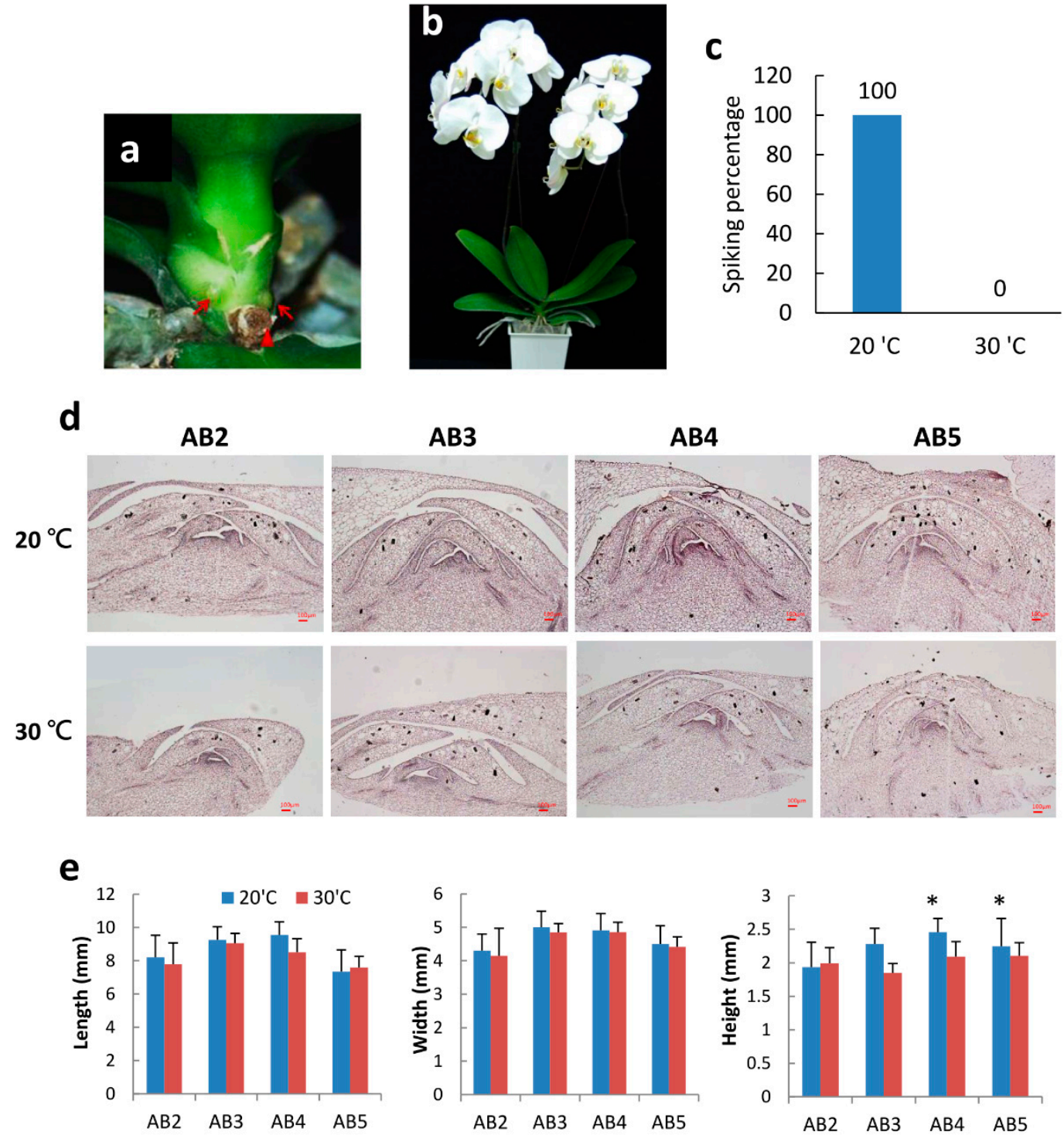

Figure 1. Effect of temperature on the growth of axillary buds of Phalaenopsis orchids: (a) Axillary buds grew in the leaf base. (b) Blooming of Phal. orchid at 3.5 months after spiking. (c) Moderate low temperature $\left(20^{\circ} \mathrm{C}\right)$ enhanced orchid spiking. (d) Morphology of axillary buds in different leaves of Phal. orchids after treated at $20{ }^{\circ} \mathrm{C}$ and $30^{\circ} \mathrm{C}$ for 2 weeks. AB2, young axillary bud in the 2 nd leaf; AB5, older axillary bud in the 5th leaf. Bar, $100 \mu \mathrm{m}$. (e) Size of axillary buds including length, width, and height. Error bars indicate the SD of 7 plants. Asterisks indicate significant difference in $20{ }^{\circ} \mathrm{C}$ compare to $30{ }^{\circ} \mathrm{C}(p<0.05$, Student's $t$-test $)$.

To do a detailed observation of axillary bud development during the spike induction process, orchid plants were kept at $20^{\circ} \mathrm{C}$ (spiking condition) and $30{ }^{\circ} \mathrm{C}$ (non-spiking condition) for two weeks. Then, axillary bud samples were collected from top to bottom from the 2nd leaf (denoted AB2) to the 5th leaf (denoted AB5) fixed in PFA buffer, dehydrated with serial ethanol, and embedded in a paraffin block, and tissue was sliced vertically to $10-\mu \mathrm{m}$ thickness. After serial dewaxing and rehydration processes, issues were stained with hematoxylin. Tissue section images were taken under microscope. Enlargement of axillary bud size was found in the axillary bud of AB3 to AB5 after 
$20{ }^{\circ} \mathrm{C}$ treatment. Outer scale number was increased, and the meristematic tissue showed enlargement (Figure $1 \mathrm{~d}$, top panel), whereas, at $30^{\circ} \mathrm{C}$, the growth of the young axillary buds (AB2 and AB3) was strongly inhibited and showed smaller size AB4 and AB5 (Figure 1d, bottom panel) compared to those at $20^{\circ} \mathrm{C}$. Quantitative measurement of the length, width, and height of the axillary bud size was carried out at two weeks after treatment. Results indicated that AB3 and AB4 had longer and wider axillary buds, indicating that these axillary buds were more mature than AB2. After $20^{\circ} \mathrm{C}$ spike induction for two weeks, axillary buds of $\mathrm{AB} 3, \mathrm{AB} 4$, and $\mathrm{AB} 5$ grew higher and have large meristems. However, small-size dormant axillary buds were found after $30^{\circ} \mathrm{C}$ treatment (Figure 1e). Normally, N2K01 mature plants can produce one to two spikes after spike induction. The position of the floral stalk will come from the 3rd to 5th leaf positions depending on the maturation of the axillary buds. It is consistent with our finding that $\mathrm{AB} 3$ to $\mathrm{AB} 5$ are larger and more mature than young $\mathrm{AB} 2$. Besides bud maturation, appropriate low temperature can induce dormancy breaking and turn on spike initiation in Phal. orchid. In this study, all N2K01 plants exhibited spiking after $20^{\circ} \mathrm{C}$ treatment; however, absolutely no spiking was found under high temperature of $30^{\circ} \mathrm{C}$ (Figure 1C).

\subsection{Identification of a bHLH Gene Responding to Spiking}

In order to understand gene profiling during orchid spiking, we performed RNAseq using the 4th axillary bud after treatment at $20^{\circ} \mathrm{C}$ (spiking condition) and $30^{\circ} \mathrm{C}$ (non-spiking condition) for two weeks (data not shown). Our team is interested in identifying the gene function of bHLH TFs, and we found that a $b \mathrm{HLH}$ gene was significantly upregulated at $20^{\circ} \mathrm{C}$ but inhibited at $30^{\circ} \mathrm{C}$, which piqued our interest to do further study. First of all, we performed RT-qPCR on this bHLH candidate in various axillary buds after $20^{\circ} \mathrm{C}$ and $30^{\circ} \mathrm{C}$ treatment for two weeks, along with $F T$, a flowering marker gene. Results indicated that this target $b \mathrm{HLH}$ gene was upregulated at $20^{\circ} \mathrm{C}$ but inhibited at $30^{\circ} \mathrm{C}$. At $20^{\circ} \mathrm{C}$, the candidate $b H L H$ gene was highly expressed in $\mathrm{AB} 2$, was second most highly expressed in $\mathrm{AB} 3$, and decreased in AB4. Similarly, at $30^{\circ} \mathrm{C}$, the candidate $b H L H$ gene was more significantly expressed in the young $\mathrm{AB} 2$ than $\mathrm{AB} 3$ and $\mathrm{AB} 4$ (Figure 2a). As a flowering marker, $F T$ was highly expressed after $20^{\circ} \mathrm{C}$ spike induction, and abundant transcripts were found in the axillary buds of AB2 and AB3, whilst $F T$ mRNA was inhibited at $30{ }^{\circ} \mathrm{C}$ (Figure $2 \mathrm{~b}$ ). As this bHLH candidate may be associated with spiking, we named it "Spike Activator 1 (SPK1)" in this study. The experiments were repeated twice, and the results were consistent. Therefore, we were interested in conducting a detailed study on the biological function of SPK1.

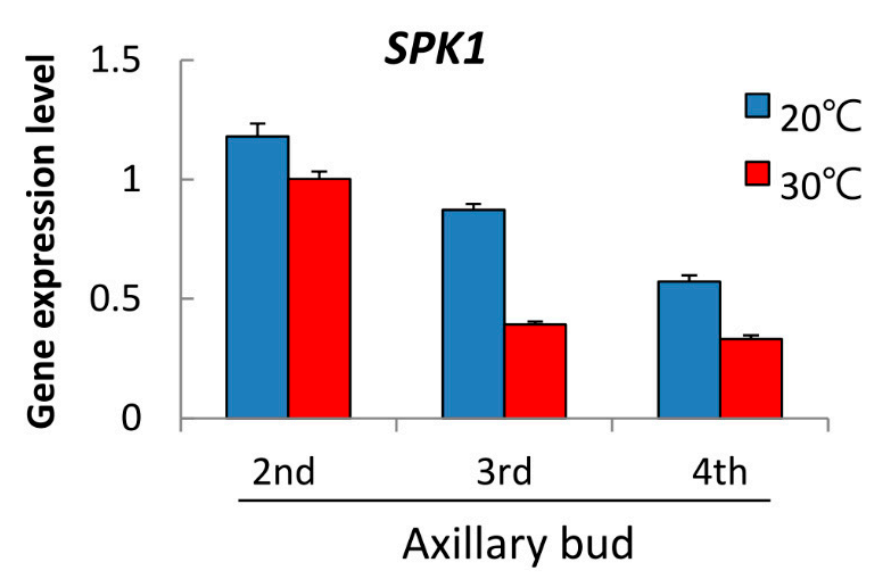

Figure 2. Cont. 


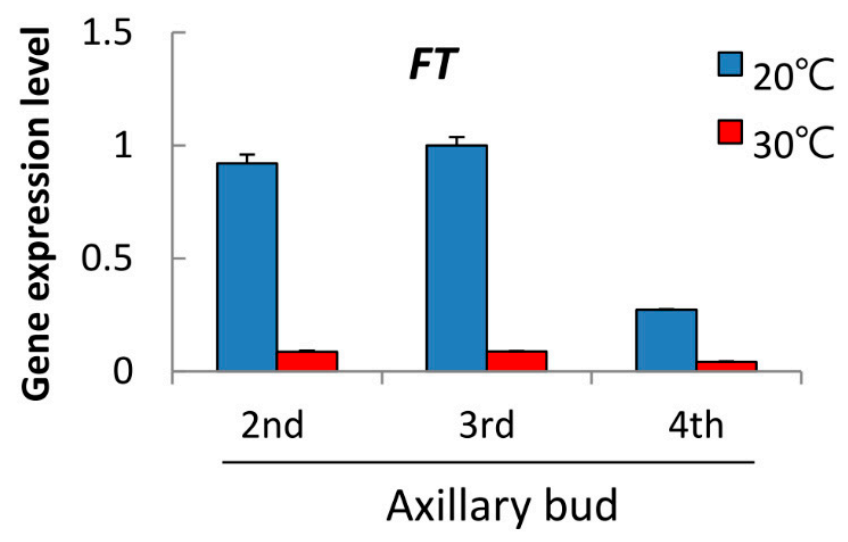

Figure 2. SPK1 responds to temperature treatments: Axillary buds of Phal. orchid after treatment at $20^{\circ} \mathrm{C}$ and $30{ }^{\circ} \mathrm{C}$ for 2 weeks were collected, and gene expression patterns of SPK1 (a) and FT (b) were detected. Relative gene expression was quantified by real-time PCR and normalized to Ubiquitin. Data are presented as mean $\pm \mathrm{SD}(n=3)$.

\subsection{Isolation of SPK1 Full-Length cDNA and Its Protein Subcellular Localization in the Nucleus}

SPK1 was blasted to PATC136668 in the Orchidstra 2.0 database [29]. It is annotated as "Similar to XP_009403078, PREDICTED: transcription factor bHLH94-like" in the database. Full-length cDNAs of SPK1 were cloned from Phal. aphrodite using the RACE PCR method. The SPK1 cDNA was $1344 \mathrm{bp}$ in length with a 912-bp coding sequence. The 5' UTR length was $213 \mathrm{bp}$, and the 3' UTR was $219 \mathrm{bp}$. Sequence data of SPK1 was deposited with the GenBank data libraries under accession number MN481612.

The gene structure of SPK1, shown in Figure 3a, indicates that SPK1 contains a bHLH domain and a DNA-binding domain and contains a nuclear localization signal (NLS). The SPK1 gene is predicted to encode a protein of 303 amino acids. Multiple alignment of the bHLH-conserved domain was carried out, and the results showed that SPK1 contains conserved basic amino acid Arg that is important for binding DNA and conserved Leu residues that are important for forming the $\alpha$-helix for protein-protein interaction (Figure 3b). Since the bHLH proteins are characterized as TFs, we wondered whether SPK1 protein was localized in the nucleus. To verify the subcellular localization, we constructed a fusion gene of the green fluorescent protein gene (eGFP) and SPK1 under the control of the 35S promoter and the nos terminator for transient expression. As a positive control, the NLS sequence was also fused to the red fluorescent protein (RFP) gene using the same regulatory elements (Figure 3c). These constructs were bombarded into orchid petal cells. As expected, with the eGFP construct alone, the GFP signal was found constitutively expressed in the nucleus as well as in the cytoplasm. However, the SPK1:eGFP fusion protein and the positive control of NLS:RFP were exclusively located in the nucleus (Figure 3d). These results confirmed that SPK1 protein is localized in the nucleus. 
a

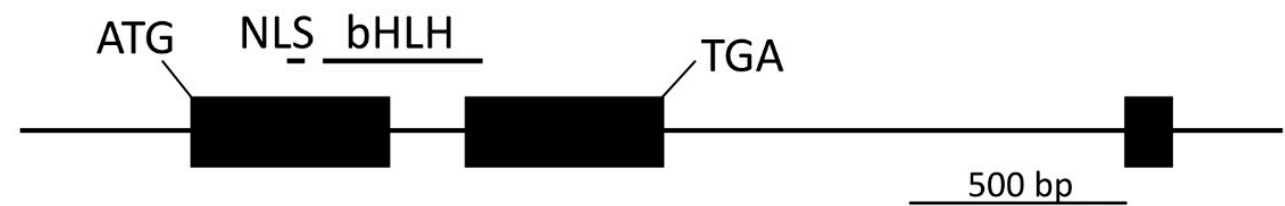

b

(1) 1

10

30

40 50 61

SPK1 (1) ENQRMTHIAVERNRRKQMNEYLAVLRSLMPASYAQRGDQAS IVGGAINYVKELQQIVQ---

PebHLH94-like (1) ENQRMTHIAVERNRRKQMNEYLAVLRS IMPASYAQRGDQAS IVGGA INYVKELQQIVQ--OsbHLH96 (1) ECQRMTHIAVERNRRRQMNEYLAVLRSIMPASYSQRGDQAS IVGGAINYVKELEQLLQ--DcbHLH96 (1) ENQRMTH IAVERNRRKQMNEYLALLRS IMPLSYAQRGDQAS IVGGA INYVKELEQLLQ--ZmbHLH96 (1) ESQRMTHIAVERNRRKQMNEYLAVLRS LMP PSYAQRGDQAS I IGGA INYAKELEQLLQ--AtbHLH94 (1) ENQRMTHIAVERNRRKQMNEYLAVLRSLMPSSYAQRGDQAS IVGGA INYVKELEHILQSME

C

P35S::eGFP-Tnos

P35S::NLS-mRFP-Tnos

P35S::SPK1-eGFP-Tnos *** \# \#* \# *

(1)

\begin{tabular}{|l|l|l|l|}
\hline P35S & eGFP & Tnos \\
\hline P35S & virD2-NLS & mRFP & Tnos \\
\hline P35S & SPK1 & eGFP & Tnos \\
\hline
\end{tabular}

d

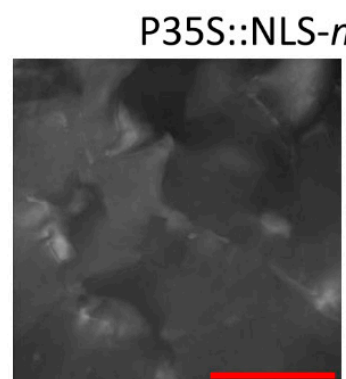

\section{MRFP-Tnos}
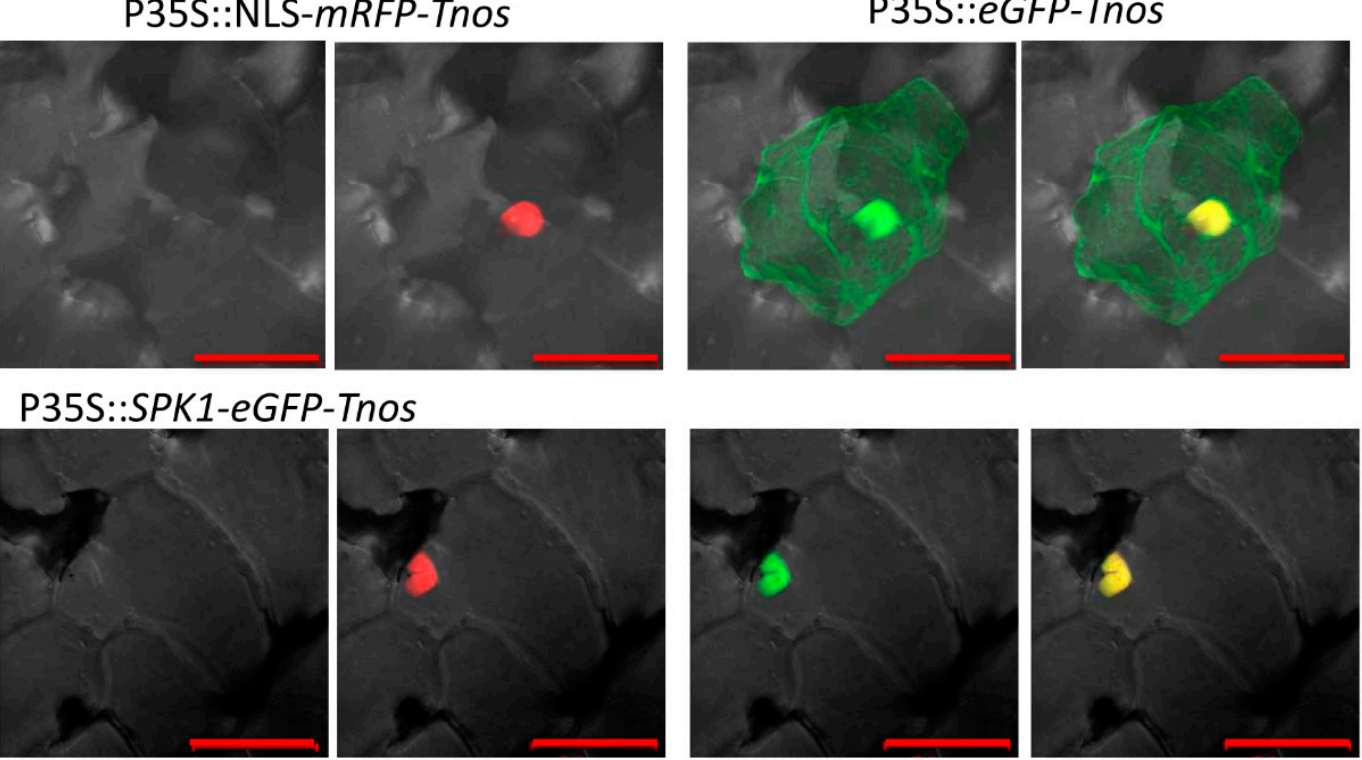

Figure 3. Gene structure, multiple alignment, and subcellular localization of SPK1: (a) Gene structure of SPK1. Lines, introns. Black boxes, exons. Bar, 500 bp. (b) SPK1 basic helix-loop-helix (bHLH) conserve domain multiple alignment. At, Arabidopsis_thaliana; Dc., Dendrobium catenatum; Os., Oryza sativa; Pe., Phalaenopsis equestris; Zm., Zea_mays. Asterisks indicate the conserved basic amino acid Arg that is important for binding DNA. Pound signs indicate conserved Leu residues important for forming the $\alpha$-helix. (c) Schemes of fusion constructs. P35S, cauliflower mosaic virus 35S promoter; Tnos, nopaline synthase gene terminator. The nuclear localization signal (NLS) domain of VirD2 fused with red fluorescent protein (mRFP) was used as the nuclear localized control. (d) Subcellular localization of SPK1 protein. Bars, $50 \mu \mathrm{m}$. 


\subsection{Phylogenetic Tree}

To determine the evolutionary relationship between SPK1 in Phal. aphrodite and other plant species, we constructed a phylogenetic tree for the SPK1 amino acid sequences from different species, including Ananas comosus, Apostasia shenzhenica, Arabidopsis thaliana, Coffea arabica, Capsicum chinense, Cymbidium ensifolium, Cinnamomum micranthum, Dendrobium catenatum, Elaeis guineensis, Oryza sativa, Phalaenopsis aphrodite, Phoenix dactylifera, Phalaenopsis equestris, Quercus suber, Setaria italica, Solanum pennellii, Vigna radiata, and Zea mays. A total of 24 full-length amino acid sequences have been used to produce a phylogenetic tree. The phylogenetic tree analysis data indicated that Phal. aphrodite SPK1 was closely related to other orchid species such as Phal. equestris, Dendrobium catenatum, and Cymbidium ensifolium. SPK1 has less similarity with AtbHLH94 (AT1G22490) (Figure 4).

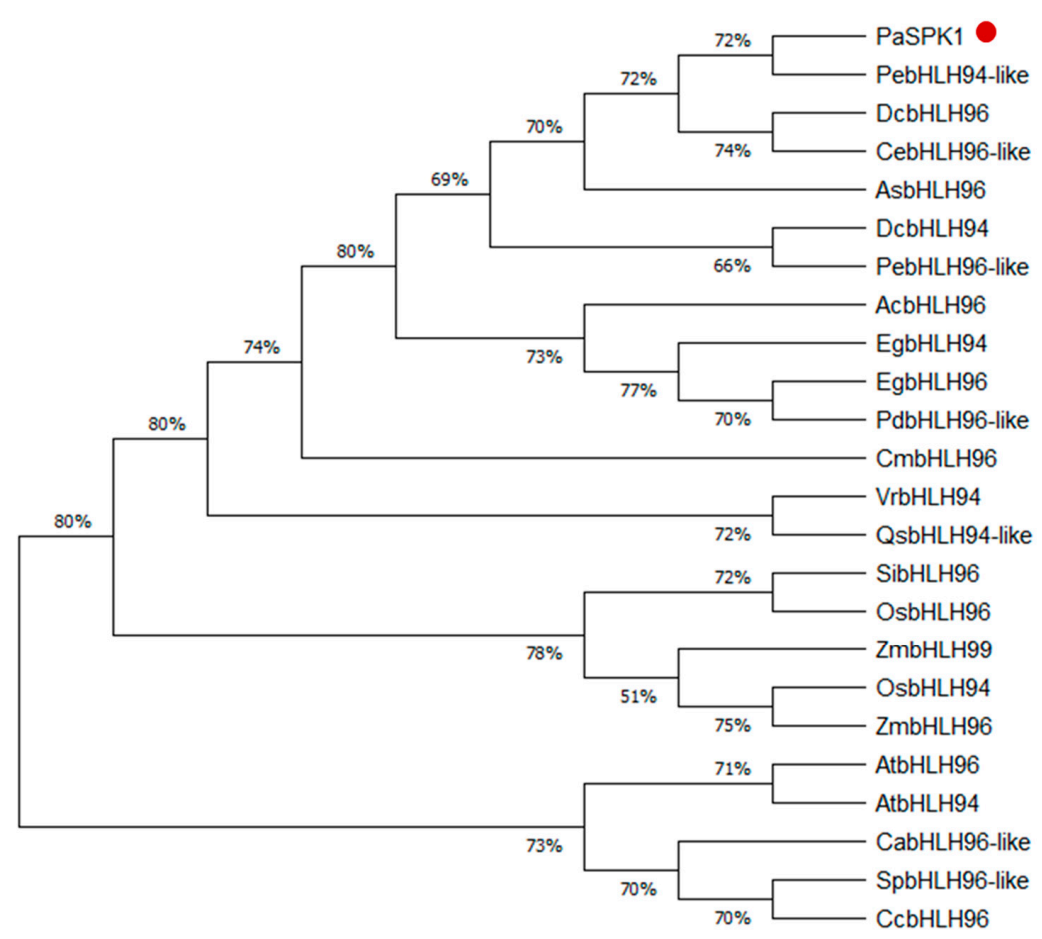

Figure 4. Phylogenetic analysis of the SPK1 full length protein: Amino-acid sequences of various species downloaded from the NCBI database, analyzed using Molecular Evolutionary Genetics Analysis version 10 (MEGA10), and constructed into a phylogenetic tree. The evolutionary history was inferred using the neighbor-joining method. The percentage of replicate trees in which the associated taxa clustered together in the bootstrap test (1000 replicates) are shown next to the branches. Boot-strapping values are indicated as percentages (when $>50 \%$ ) along the branches. The evolutionary distances were computed using the Poisson correction method and are in the units of the number of amino-acid substitutions per site. Ac, Ananas comosus; As, Apostasia shenzhenica; At, Arabidopsis thaliana; Ca, Coffea arabica; Cc, Capsicum chinense; Ce, Cymbidium ensifolium; Cm, Cinnamomum micranthum; Dc, Dendrobium catenatum; Eg, Elaeis guineensis; Os, Oryza sativa; Pa, Phalaenopsis aphrodite; Pd, Phoenix dactylifera; Pe, Phalaenopsis equestris; Qs, Quercus suber; Si, Setaria italica; Sp, Solanum pennellii; Vr, Vigna radiata; and Zm, Zea mays.

\subsection{Gene Expression Patterns of SPK1}

To understand the gene expression pattern of SPK1 in orchid, RNA samples from various tissues/organs of Phal. orchid were collected; the RNA was extracted, and quantitative RT-PCR (RT-qPCR) was carried out. It was found that SPK1 gene was highly expressed in the young tissues such as root tip, shoot apex, axillary bud, and developing young spikes but that there was less expression in the leaf and mature flower organs (Figure 5a). In situ hybridization data revealed that SPK1 mRNA 
was expressed in the young tissues of the axillary bud, developing young flower buds, and root tip (Figure 5b-h). Close-up observation of SPK1 gene expression pattern in different ages of axillary buds indicated that the SPK1 ISH-positive signal is expressed in the meristematic tissues, developing scales, and vascular bundles of young AB2 and AB3 (Figure 5b,c), with less ISH signal in the mature axillary bud tissue of AB4 (Figure 5d). In the top portion of developing young floral spikes, flower buds were initiated and SPK1 was expressed broadly in flower bud primordia and more restricted in the meristem and vascular bundle (Figure 5e). Gradually, when the flower bud organ was differentiated, the SPK1 RNA ISH signal was restricted in the meristematic tissues. Moreover, the vascular bundle of the floral spikes also had a strong ISH signal (Figure 5f). Similarly, the vascular bundle of the root also expressed SPK1 gene. A strong ISH signal was observed in the root apical meristem and elongation zone (Figure 5g). Magnification of root image indicated that SPK1 gene was expressed in the root cap, meristem, epidermis, and cortex; high in the phloem; and detectable in the xylem (Figure 5h). We also carried out ISH using SPK1-sense probe (as a negative control) in the relevant tissues of Figure 5. As shown in the Figure S1, nonspecific hybridization signal (i.e., background signal) was relatively weak using the sense probe of SPK1. To observe the morphology of tissues, all tissues used for the ISH experiment were also stained with hematoxylin and are shown in Figure S2.
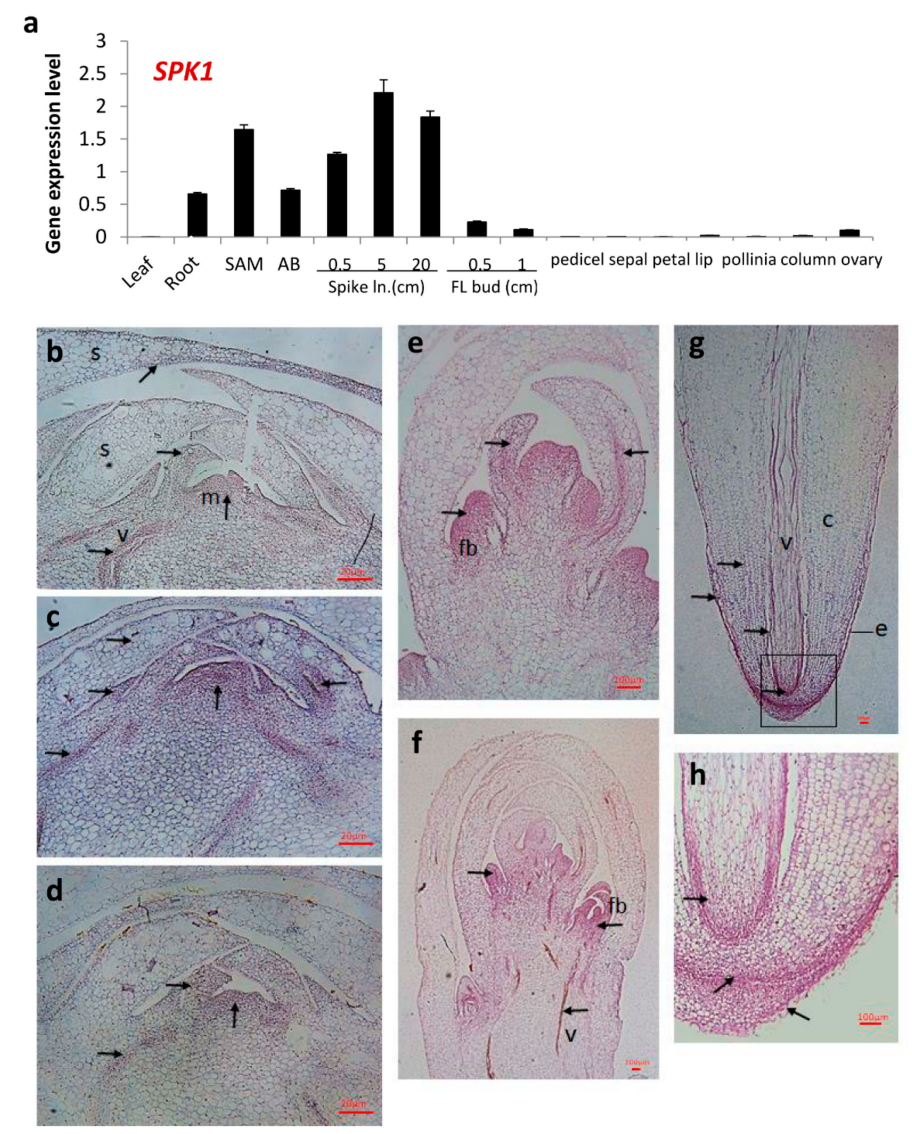

Figure 5. Gene expression patterns of SPK1 in Phal. Orchid: (a) RT-qPCR showed deferential gene expression patterns of SPK1 in various tissues of Phal. orchid. Relative gene expression was quantified by real-time PCR and normalized to Ubiquitin. Data are presented as mean $+\mathrm{SD}(n=3)$. RNA in situ hybridization of SPK1 antisense probe to various vertical sections for axillary buds of AB2 (b), AB3 (c), AB4 (d), young spike at $5 \mathrm{~cm}$ in length (e), spike at $10 \mathrm{~cm}$ in length (f), root tip (g), and magnified image of root tip (h). c, cortex; e, epidermis; m, meristem tissues; rc, root cap; s, scale; v, vascular bundle. The boxed area in (g) is magnified in (h). Arrows point to In Situ Hybridization (ISH)-positive signal. Scale bars: $20 \mu \mathrm{m}$ (Figure 5b-c), $100 \mu \mathrm{m}$ (Figure 5e-h). 


\section{6. bHLH35 Was Upregulated by High Temperature}

We also found another bHLH gene, bHLH35 (PATC131347) from the RNAseq data. RT-qPCR showed that $b H L H 35$ was highly expressed in the young tissues of shoot apex, axillary bud, and $0.5 \mathrm{~cm}$ young spikes, as with SPK1 (Figure 6a). However, bHLH35 was expressed differently to SPK1 in response to temperature stimuli. It was found that $b H L H 35$ was expressed at very low levels in the axillary buds after $20^{\circ} \mathrm{C}$ treatment, but it was highly upregulated at $30^{\circ} \mathrm{C}$ (Figure 6b). It is therefore postulated that bHLH35 may play an inhibitory role in spiking.
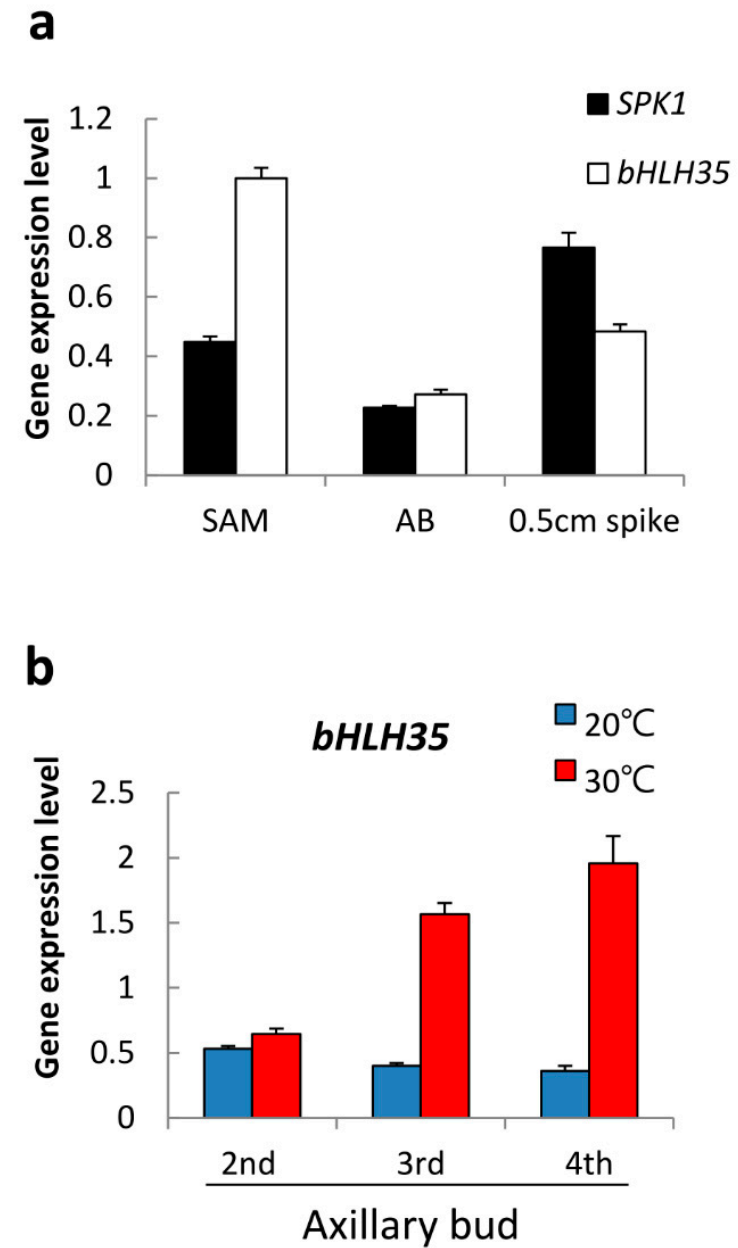

Figure 6. Gene expression patterns of bHLH35 in Phal. Orchid: (a) bHLH35 is highly expressed in the shoot apex (SAM), axillary bud (AB), and young spikes of $0.5 \mathrm{~cm}$ length. (b) High temperature at $30{ }^{\circ} \mathrm{C}$ upregulated $b H L H 35 \mathrm{mRNA}$ but it was downregulated at $20^{\circ} \mathrm{C}$. Relative gene expression was quantified by real-time PCR and normalized to Ubiquitin. Data are presented as mean \pm SD $(n=3)$.

\subsection{SPK1 and bHLH35 Form a Heterodimer}

In general, bHLH TFs can form homodimers or heterodimers with other bHLH TFs and form a large variety of dimers to regulate distinct cellular and developmental processes. To know whether SPK1 and bHLH35 proteins formed a dimer, bimolecular fluorescence complementation (BiFC) assays were carried out. BiFC result showed that yellow fluorescent protein (YFP) signals were detected only in the nucleus of the orchid cells when co-expressing both NYN1-SPK1 and CYN1-SPK1, or co-expressing NYN1-bHLH35 and CYN1-bHLH35, indicating that SPK1 and bHLH35 itself can form a homodimer (Figure 7a). It was interesting to find that, in either co-expression of both NYN1-SPK1 and CYN1-bHLH35 or co-expression NYN1-bHLH35 and CYN1-SPK1, YFP signals were detected. These results confirmed that SPK1 and bHLH35 can form a heterodimer complex in the cell nucleus 
(Figure 7a). Next, we performed yeast two-hybrid (Y2H) analysis to determine whether bHLH35, as bait, interacts with the prey, SPK1. Our Y2H results indicated that the SPK1 and bHLH35 proteins are not self-activated. Only the yeast strains co-expressing both SPK1 and bHLH35 grew normally on stringent selection media (Figure $7 \mathrm{~b}$ ). Hence, BiFC and $\mathrm{Y} 2 \mathrm{H}$ data confirmed that SPK1 can form homodimer; moreover, SPK1 can form a heterodimer complex with bHLH35.

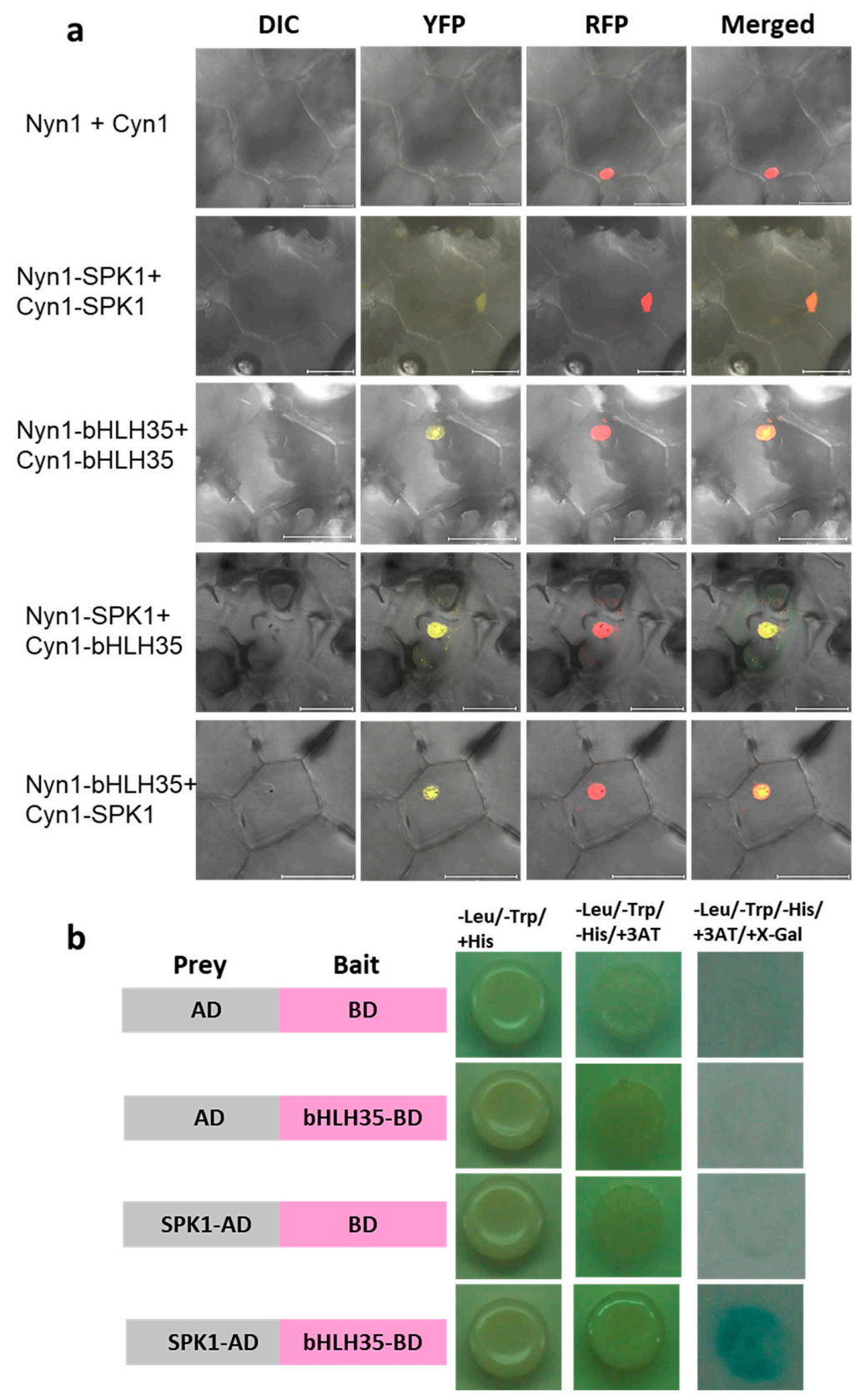

Figure 7. Protein-protein interaction between SPK1 and bHLH35: (a) bimolecular fluorescence complementation (BiFC) indicated SPK1 and bHLH35 can form a homodimer and that these two proteins can interact to form a heterodimer. The NLS domain of VirD2 fused with mRFP was used as the nuclear localized control. Bar: $50 \mu \mathrm{m}$. (b) yeast two-hybrid (Y2H) assays. Constructs expressing the full-length SPK1 were cloned into the prey vector pGADT7 (AD), and bHLH35 were introduced into the bait vector pGBKT7 (BD). Yeast strains were tested for growth in selective medium lacking Leu, Trp, and His and supplemented with 3-amino-1,2,4 triazole and X-Gal. 


\subsection{Verification of SPK1 Function}

In order to verify the biological function of SPK1 in orchid, we used a VIGS technique. The gene-specific region of SPK1 was isolated and cloned into the pCymMV-Gateway vector [30]. The VIGS gene construction maps are shown in Figure S3. After agrobacterium infiltration, orchid plants were moved to a $20^{\circ} \mathrm{C}$ growth chamber to induce spiking. At 6 weeks after VIGS treatment, axillary bud samples were collected, RNA was isolated, and RT-qPCR was performed. The results showed that after VIGS, virus CymMV gene was detected, indicating that VIGS-transmitted viral vectors are effective in orchid plants. SPK1 gene expression was not altered in the AB3 of vector only control but showed sharp downregulation in the VIGS-spk1 plant (Figure 8b). This showed that the gene silencing SPK1 target gene is effective in the AB3 of VIGS-spk1 plant. It was interesting to discover that, in the developing AB3 (the latter might develop to the 2nd floral spike), VIGS-spk1 orchid also significantly downregulated CYCB and EXPA8 but only slightly decreased FT (Figure 8d-f). Meanwhile, in the axillary bud of AB4 (more mature than AB3 but later will develop to the 1st floral spike), some VIGS-spk1 plants have less gene silencing effects and expressed high SPK1, CYCB, EXPA8, and FT transcripts (Figure S4). These results suggest that $\mathrm{AB} 4$ is already mature before VIGS treatment and that the mature axillary buds immediately respond to $20{ }^{\circ} \mathrm{C}$ spike induction, turn on spiking signal, and upregulate spiking genes. It is interesting to find that $b H L H 35$ is upregulated whenever SPK1 mRNA is downregulated in the VIGS-spk1 plants (Figure 8C and Figure S4C).
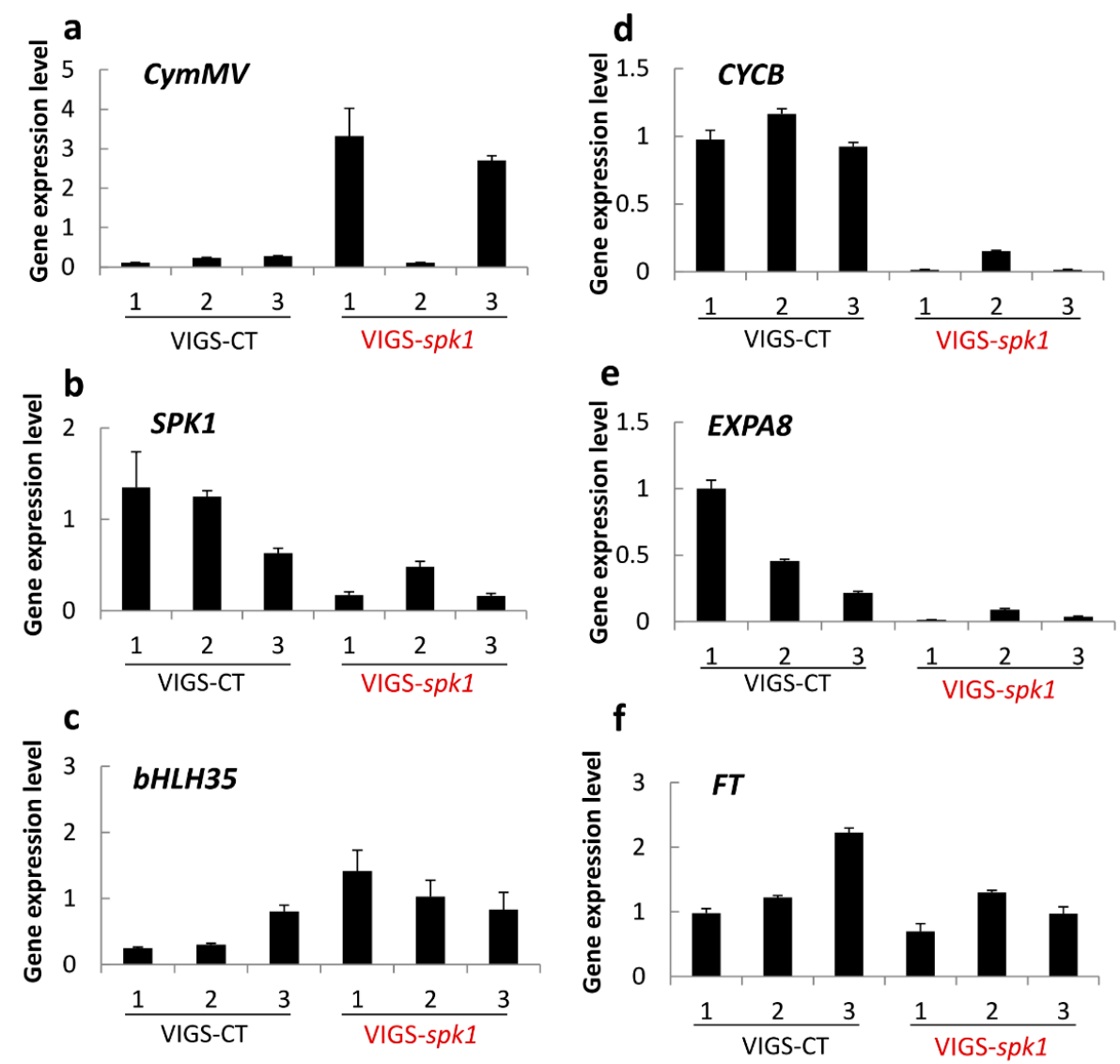

Figure 8. Cont. 


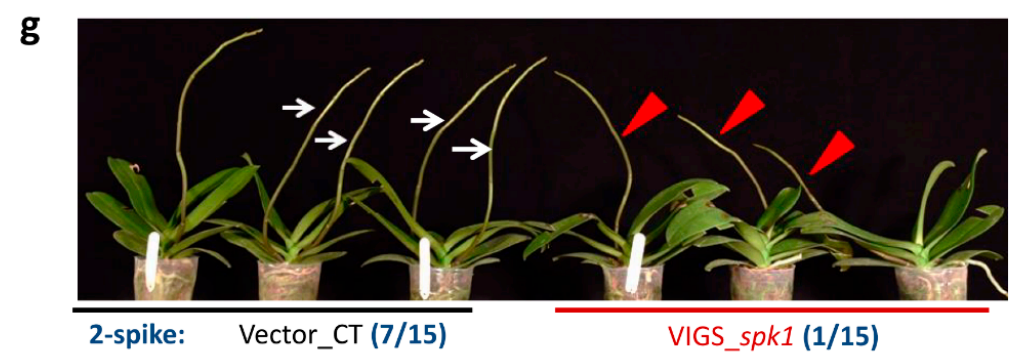

Figure 8. Validation of gene function using a Virus-induced gene silencing (VIGS) approach: VIGS of SPK1 altered gene expression patterns of CymMV (a), SPK1 (b), bHLH35 (c), CYCB (d), EXPA8 (e), and FT (f) in the 3rd axillary bud. Relative gene expression was quantified by real-time PCR and normalized to Ubiquitin. Data are presented as mean \pm SD $(n=3)$. (g) VIGS-spk1 affected double spiking rate of Phal. aphrodite cv. N2K01. Bar, SD of three replications. Arrows point to the double spikes; arrowhead points to the single spike. Photograph was taken at 3.5 months after spike induction.

After VIGS for 3.5 months, spike number was recorded. Results showed that all orchid plants produced at least one floral stalk. It was found that all orchid plants can produce at least one spike after spike induction and that 7 out of 15 plants produced double spikes in the vector-only control, whilst a mere 1 out of 15 VIGS-spk1 plants produced double spikes. Phenotype of spiking at 3.5 months after VIGS is shown in Figure 8g. The VIGS experiment clearly suggested that knockdown of SPK1 tends to inhibit young axillary bud development and to reduce double spiking rate due to downregulation of SPK1 and genes associated with spiking.

\section{Discussion}

\subsection{Physiology of Spiking in Phalaenopsis Orchid}

Precise control of spiking is very important for the Phalaenopsis orchid industry and trading. A mature Phalaenopsis orchid at the five-leaf stage actually has five different sizes of axillary buds in the plant. Spike initiation first requires a mature axillary bud. In general, the 1st floral stalk will produce the most mature bud from the 3rd to 5th leaves (Figure 1). If nutrient condition and the maturation of the axillary bud is good, the 2nd most mature axillary bud will develop into the 2nd floral stalk and produce a double-spike plant. If the maturity of two buds are similar, they will spike simultaneously and produce uniform floral stalks that are a sought-after horticultural trait. Double spikes increase flower numbers and therefore increase the price of orchids.

Besides axillary bud maturation, orchid spiking is temperature dependent; $30{ }^{\circ} \mathrm{C}$ retards the transition from the vegetative to the reproductive phases. Actually, the size of AB4 and AB5 are medium large at $30{ }^{\circ} \mathrm{C}$ but, so far, no spiking has been found, which may be due to dormancy. That means, besides axillary bud maturation, moth orchids need moderately low temperatures to break dormancy and to trigger spiking. This study shows that $20^{\circ} \mathrm{C}$ upregulated SPK1 and FT mRNA in axillary buds and triggered floral spike initiation (Figure 2). Inducer of CBF expression 1 (ICE1) encodes a MYC-like bHLH transcriptional activator and regulates the transcription of $C B F$ genes in the cold [20]. Moderately low temperature promotes orchid spiking. However, the temperature regime for orchid spiking is not as cold as some plants need for vernalization [31]. In fact, orchid spiking is a complex process and may have a distinct flowering pathway, and its underlying mechanism requires further extensive study. Moreover, plant hormones may play an important role in orchid spiking, but so far, not much molecular evidence exists in this area. Moderately low temperatures may help plants release ABA, alter hormone homeostasis, or accumulate auxin and cytokinin to enhance cell proliferation. Besides temperature, other environmental factors such as light, nutrient acquisition, etc. might contribute to orchid axillary bud maturation and spike initiation. Of note, protecting orchid from stress conditions can prevent axillary bud degeneration, maximize axillary bud growth and 
maturation, and finally enhance spiking. Overall, spiking in Phalaenopsis orchid is controlled by genetic and environmental cues.

\subsection{Identification of a Novel Orchid Spiking Activator, SPK1}

This study identified a novel bHLH TF, SPK1, which contributes to spike induction in moth orchid. Protein structure of SPK1 comprises a conserved helix-loop-helix domain which enables protein-protein interaction. It contains a DNA-binding domain and may bind to the promoter of the downstream target gene. In fact, SPK1 has a conserved basic amino acid Arg that is important for binding DNA (Figure 3b, asterisks). A functional HLH domain is found, and an NLS domain required for nuclear localization is found in SPK1 (Figure 3a). Subcellular localization showed that SPK1 protein localizes to the nucleus (Figure 3d). Overall, SPK1 is a typical bHLH and plays a role as a TF. Phylogenetic tree results showed that SPK1 is evolutionarily conserved in orchid species but less similar to other plant species (Figure 4). That may be because its natural habitat and the spiking/flowering requirement of orchid is unique compared to other plant species.

\subsection{SPK1 Controls Meristematic Cell Proliferation}

SPK1 is highly expressed in the meristematic tissues, as revealed in our RT-qPCR and ISH data (Figure 5). It was found that the SPK1 gene expression pattern in the axillary bud is age dependent. It is highly expressed in young AB2 but gradually reduced in the older axillary buds of AB4 and AB5 (Figure 2a). These results suggest that SPK1 may regulate the early stage of axillary bud development for meristem cell proliferation and organ differentiation. RNA in situ analysis data revealed that SPK1 mRNA is strongly expressed in the meristem of axillary buds and primordia of the flower bud (Figure 5). Presumably, SPK1 might mediate flower bud organ differentiation. Moreover, SPK1 was found highly expressed in the root tip. Our data further showed that SPK1 is clearly present in the meristematic tissues and may play an essential role in organelle differentiation and cell proliferation. In addition, ISH data also revealed that SPK1 transcripts are expressed in the vascular bundle of the root, axillary bud, and young floral stalk (Figure 5), indicating that SPK1 may be involved in long-distance RNA movement in orchids. Plants utilize proteins and RNA as non-cell-autonomous signaling macromolecules to mediate local and long-distance regulation. RNA delivery via the phloem allows flexibility and fine-tuning of developmental programs to ensure newly developing tissues are optimized for performance under different environmental conditions [32]. For example, phloem long-distance trafficking of GIBBERELLIC ACID-INSENSITIVE RNA regulating leaf development has been reported [32].

\subsection{SPK1 Controls Orchid Spiking}

Gene expression analysis revealed that $S P K 1$ is expressed in the meristematic tissues of the root and reproductive organs. Under moderately low temperature suitable for spiking, SPK1 gene is upregulated, but under high temperature, it is downregulated and reduced SPK1 gene expression (Figure 2a). SPK1 gene co-expressed with $F T$ at $20{ }^{\circ} \mathrm{C}$ (Figure 2), implying that SPK1 may be involved in the spiking/ flowering pathway of orchid. Surprisingly, our VIGS experiment showed that downregulation of the SPK1 gene just slightly suppressed the gene expression level of $F T$ (Figure 8f), further suggesting that SPK1 is partly involved in the pathway of FT. Interestingly, in the axillary bud of VIGS-spk1 plant, the SPK1 gene is downregulated (Figure 8b), but in turn bHLH35 is upregulated (Figure 8C). Clearly, bHLH35 and SPK1 act as antagonists and bHLH35 may act as a repressor in the spiking pathway.

We also found that $C Y C B$ and EXPA8 gene expression levels are significantly downregulated in the axillary bud of the VIGS-spk1 orchid (Figure 8d,e). Presumably, SPK1 may regulate cell cycle genes for cell division. It has been reported that increased expression of cell cycle genes increased mitotic activity and broke dormancy [13]. Moreover, VIGS-spk1 plants reduce EXPA8 gene expression, which may reduce cell elongation. Therefore, VIGS of SPK1 significantly inhibited the 2nd floral spike development 
(Figure 8g). All orchid plants produced the 1st floral spike (from AB4) whether they were VIGS-spk1 treated because the orchid plants used in this study were mature and size of the axillary bud was big (Figure 1) before the plants were subjected to VIGS Agroinfiltration. Exposure to $20^{\circ} \mathrm{C}$ treatment favors buds breaking dormancy. The axillary bud meristem senses the environmental stimuli and turns on spiking processes. Typically, the VIGS silencing gene occurs at 4 to 6 weeks post-inoculation; therefore, our VIGS on mature orchid plants could inhibit the growth of the young bud and effectively inhibit the 2nd floral spike induction but not inhibit the 1st floral spike. These results indicate that gene hierarchy of SPK1 acts upstream of these known markers associated with flowering, cell cycle, and cell elongation. Therefore, SPK1 TF may regulate several biological functions including axillary bud maturation, spiking time, cell differentiation, and cell elongation, etc. Clearly, orchid spiking is a complex process. Precise coordination between TFs and spatial temporal expression of spiking genes is required for floral spike initiation.

\subsection{Coordination among bHLH TFs for Spiking}

Our protein-protein interaction data indicated that SPK1 protein can form a homodimer (Figure 7). Presumably, SPK1 homodimer might modulate downstream genes associated with axillary bud maturation and spiking activation genes. At $20^{\circ} \mathrm{C}, S P K 1$ gene expression level is high (Figure 2a). However, the specific downstream genes that are directly regulated by SPK1 TF remain unknown, whether $C Y C B$ and EXPA8 are regulated by SPK1 needs further investigation. It was found that $b H L H 35$ co-expresses with SPK1 in the meristematic tissues but that $b H L H 35$ is upregulated at high temperature and may act as a repressor of spiking (Figure 6). Our in vivo $\mathrm{Y} 2 \mathrm{H}$ and BiFC data demonstrated that bHLH35 and SPK1 proteins can form a heterodimer (Figure 7). Presumably, the heterodimer of SPK1/bHLH35 may inhibit the transactivation of downstream spiking gene(s). It has been reported that FD (flowering activator) can interact with TFL1 (flowering repressor) and regulate flowering rhythm [33]. It is believed that precise regulation of the TFs is essential for meristem maintenance and to understand how orchids cope with fluctuation of environments and morphological change. Interaction between SPK1 and bHLH35 might regulate temperature-dependent spike induction in moth orchid.

\subsection{Proposed Model for SPK1 Mediates Spiking of Phal. Orchid}

As shown in Figure 9, under $30^{\circ} \mathrm{C}$, although the axillary bud is mature, it is arrested with no spiking (Figure 1). When the axillary bud is exposed to high temperature, bHLH35 is significantly upregulated (Figure 6b). Therefore, bHLH35 may act as a repressor that inhibits the transactivation of the downstream spiking gene(s), thus inhibiting cell proliferation and causing axillary bud arrested growth with bud size remaining small (Figure 1). We hypothesize that under $30^{\circ} \mathrm{C}$ non-spiking condition, bHLH35 might bind to E-box in the promoter of spiking gene(s), inhibit SPK1 homodimer complex binding to the E-box, and fail to transactivate the downstream spiking gene(s).

However, at moderately low temperature of $20^{\circ} \mathrm{C}$ that is good for orchid spiking, SPK1 is found highly expressed in the meristem of axillary bud (Figure 2a, Figure 5, and Figure 9b), and FT mRNA is similarly upregulated in the axillary bud (Figure $2 b$ ), further suggesting that the orchid is ready for spiking/flowering. Our VIGS experiments demonstrated that, when VIGS-spk1 orchid downregulated $S P K 1$, it also significantly downregulated the gene expression levels of CYCB and EXPA8 mRNAs (Figure 8), suggesting that gene hierarchy of SPK1 is located upstream of $C Y C B$ and EXPA8. This study shows two bHLH TFs (SPK1 and bHLH35) that fine-tune axillary bud meristem development and control spike initiation in orchid. 

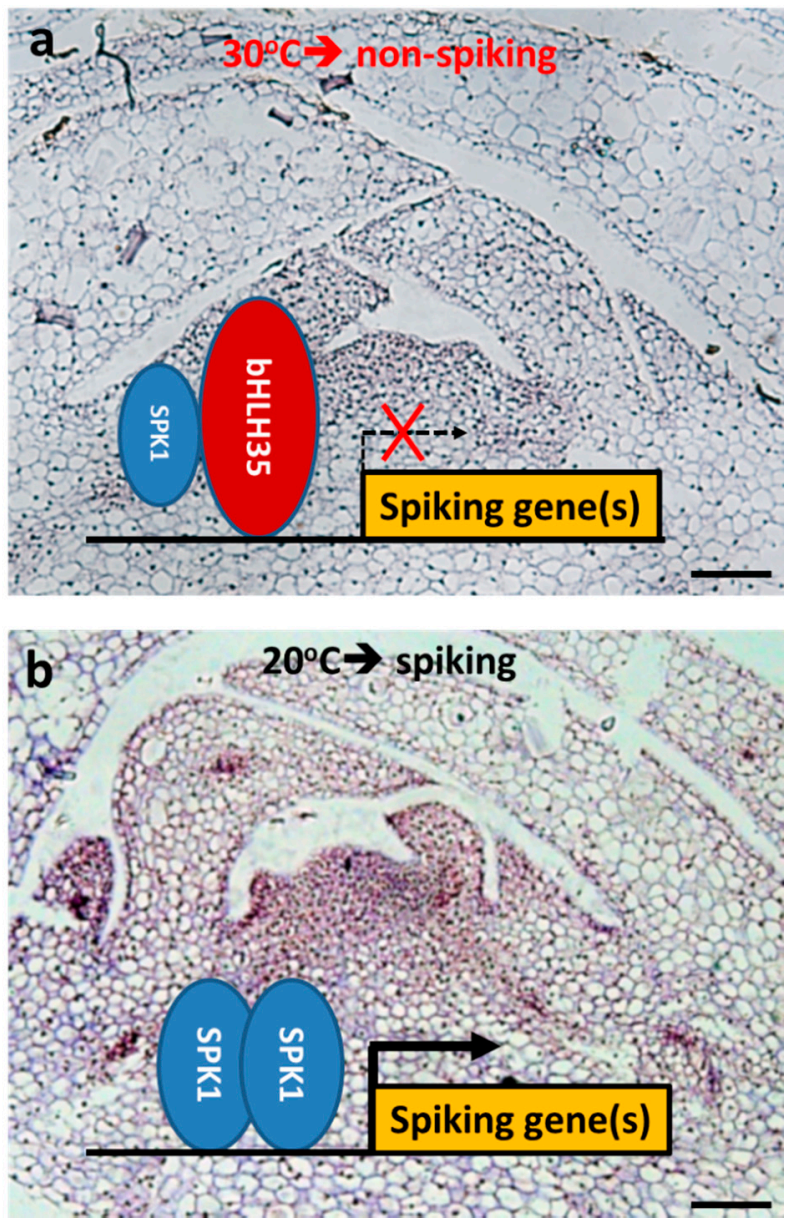

Figure 9. Proposed molecular mechanism underlying SPK1 regulation of axillary bud development and spiking in Phal. orchid: (a) At $30{ }^{\circ} \mathrm{C}$ non-spiking condition, SPK1 gene is downregulated but bHLH35 is upregulated. SPK1 and bHLH35 can form a heterodimer and may bind to E-box in the promoter of spiking gene(s) and therefore inhibit the transactivation of downstream spiking gene(s). (b) At the $20^{\circ} \mathrm{C}$ spiking condition, SPK1 is highly expressed in the meristem of axillary bud (ISH signal showed purple color). SPK1 forms a homodimer and may bind to E-box in the promoter of spiking gene(s), such as $F T, C Y C B$, and EXPA8 for cell division and elongation, and may promote orchid spiking at $20{ }^{\circ} \mathrm{C}$. Bars, $20 \mu \mathrm{m}$.

\subsection{Research Prospects for Control Spiking in Orchid}

Double-spike Phalaenopsis orchids produce more flowers and have greater market value than those with single spikes. Controlling axillary bud development and maturation is important to meet seasonal market demands. Furthermore, manipulation and control of spiking is essential in the orchid industry for international trading. This study showed that SPK1 regulates growth of orchid meristematic tissues (root tip, axillary bud, young spike, and flower primordium) and cell proliferation and mediates spiking in Phal. orchid. It is believed that regulation of spiking is a complex pathway and that discovery of more key genes/TFs expressed in the meristem of axillary bud will extend our understanding of the molecular basis of the spiking pathway in moth orchid.

\section{Materials and Methods}

\subsection{Plant Materials and Growth Conditions}

Phalaenopsis orchid (P. aphrodite subsp. formosana) cv. N2K01 orchid plants at the five-leaf stage were purchased from Chain Port Orchid Nursery (Ping Tung, Taiwan). For spike induction, orchid plants 
were kept in a growth chamber set at a constant $20^{\circ} \mathrm{C}$. For non-spiking treatment, orchids were kept in a $30^{\circ} \mathrm{C}$ growth chamber. LED white light was installed in the two growth chambers with a light intensity of $150 \mathrm{mmol}^{-1} \cdot \mathrm{m}^{-2} \cdot \mathrm{s}^{-1}$ and $12 \mathrm{~h}$ light/12 h dark cycle. After spiking, orchids were then cultivated in the Academia Sinica Biotechnology Center greenhouse in Tainan City in Southern Taiwan. The greenhouse is under a $70 \%$ shade curtain to prevent orchids from sunburn, and the temperature was controlled at $24 \pm 2{ }^{\circ} \mathrm{C}$.

\subsection{Cloning of the SPK1 Gene from Phal. aphrodite}

To isolate full-length cDNA, the rapid-amplification of cDNA ends (RACE) technique was performed using the SMART RACE cDNA Amplification Kit (Clontech). Gene-specific primers were designed based on the partial cDNA sequences of SPK1 (PATC136668); 5'-GGCTCT CCACAATCGTTACCTCTATATCGG-3' ${ }^{\prime}$ and $5^{\prime}$-GATCTGAAGCCGCTTGCGAGTTTCTTC-3' primers were used for $5^{\prime}$ and $3^{\prime}$ RACE PCR, respectively. RACE PCR was performed according to the manufacturer's instructions.

\subsection{Phylogenetic Analysis}

Protein sequence of SPK1 was blasted in the National Center for Biotechnology Information (NCBI) database. Highly similar sequences were retrieved, and a phylogenetic tree was generated with the neighbor-joining method [34] using Molecular Evolutionary Genetics Analysis, version 10 (MEGA X) software [35] and constructed into a phylogenetic tree. The percentage of replicate trees in which the associated taxa clustered together in the bootstrap test (1000 replicates) are shown next to the branches. The evolutionary distances were computed using the Poisson correction method [36] and are in the units of the number of amino-acid substitutions per site.

\subsection{Gene Expression Analysis}

Total RNA was extracted from different tissues of Phalaenopsis cv. N2K01 using Trizol reagent (Invitrogen, Carlsbad, CA). Total RNA was DNase treated, and then, 1 mg RNA was reverse-transcribed using M-MLV (Promega) according to the manufacturer's instructions. All RT-qPCR reactions were performed for 40 cycles with KAPA SYBR FAST qPCR Master Mix 2× (Kapa Biosystems, Woburn, MA, USA). Primers used for PCR are listed in Supplementary Table S1. The real-time RT-PCR reaction was performed in triplicate on the C1000TM Thermal Cycler (Bio-Rad). Relative gene expression level was normalized to the constitutively expressed gene Ubiquitin (PATC150470) as a control.

\subsection{Tissue Section}

Orchid tissue samples of axillary buds (AB2 to AB5), top portion of young spikes at $5 \mathrm{~cm}$ length and $10 \mathrm{~cm}$ length, and $1 \mathrm{~cm}$ length of root tip tissue were collected. Paraffin tissue section followed the previous protocol [12]. In brief, tissue samples were fixed in ice-cold $4 \%$ Paraformadehyde buffer, dehydrated with serial ethanol, and embedded in a paraffin block, and tissue was sliced vertically to $10 \mu \mathrm{m}$ thickness.

\subsection{In Situ Hybridization (ISH)}

ISH protocol was as described previously [37] with some modification. In brief, SPK1 was cloned using gene specific primers of $5^{\prime}$ - CATGAGGAAGAAGGGTTCTATACTTC $-3^{\prime}$ and $5^{\prime}$ - GCCTT CTCATCATTTGCCTCAT-3' (213 bp). In situ hybridization of $S P K 1$ probe was performed at $48^{\circ} \mathrm{C}$ with $40 \mathrm{ng}$ of DIG-labeled RNA probe. Anti-DIG is in 1:700 dilution. 


\subsection{Bimolecular Florescence Complementation Assay}

Full-length cDNAs of SPK1 and bHLH35 were independently introduced into pJET1.2 (Thermo Scientific). The sequence for the N-terminal amino acid residues 1 to 174 of YFP was then in-frame fused to the sequence of the C-terminal region of the tested proteins, while the sequence of the C-terminal amino acid residues 175 to 239 of YFP were in-frame fused to the sequence of the N-terminal end of the proteins. Next, the tested genes were introduced into pSAT5-DEST_CYN1 and pSAT4(A)-DEST_NYN1. Ballistic bombardment-mediated transient transformation was performed as described previously [38]. The bombarded explants were incubated in the dark for $24 \mathrm{~h}$, and florescence images were photographed on a LSM780 Plus ELYRA S.1 confocal microscope with a Plan-Apochromat 403/1.4 oil objective lens (Zeiss, Gina, Germany).

\subsection{Yeast-Two Hybrid (Y2H)}

The Matchmaker GAL4 two-hybrid system (Clontech,) was used for Y2H assays. The full-length cDNA of SPK1 was cloned into pGAD-T7 (Clontech). Full-length of bHLH35 was cloned into pGBK-T7 (Clontech), respectively. Protein interactions in vivo in yeast were carried out according to a previous report [39].

\subsection{Virus-Induced Gene Silencing (VIGS)}

VIGS and Agrobacterium tumefaciens-mediated transient expression was performed in Phalaenopsis orchids to verify transient loss-of-function assays of SPK1 in orchids. Gene-specific regions of SPK1 was cloned using the primers referenced in Supplementary Table S1 to obtain 212 bp fragments; it was then cloned into pCymMV-Gateway vectors [30] (Figure S3) and transformed into the agrobacterium strain EHA105. The VIGS vector with the target gene was infiltrated into the 1st and 2nd new established leaves of Phalaenopsis orchids in 15 biological replicates. At 6 weeks post-VIGS inoculation, three vector-only control and VIGS-spk1 plants each were randomly selected and axillary bud samples of AB3 and AB4 were collected, RNA were isolated. Gene expression patterns of $C y m M V, S P K 1, E X P A 8$, and $C y c B$ were checked using RT-qPCR.

\subsection{Statistical Analysis}

Data shown are the means with standard errors of at least 7 independent biological samples. The data were statistically analyzed by Student's $t$-test.

Supplementary Materials: Supplementary materials can be found at http://www.mdpi.com/1422-0067/20/21/ 5406/s1.

Author Contributions: S.-S.K. conceived and designed the experiments. Y.-J.L., M.-J.L., H.-C.H., T.-K.C., and T.-T.Y. performed the experiments. S.-S.K., Y.-J.L., and M.-J.L. analyzed the data. S.-S.K. wrote the paper.

Funding: This work was financially supported by the Innovative Translational Agricultural Research Program (iTAR) to S.-S.K.

Acknowledgments: We are grateful to Hsin-Hung Yeh for providing the VIGS vector for this study. We thank the GMO greenhouse of the Biotechnology Center in Southern Taiwan (AS-BCST) for providing space for growing plants and technical support. We thank the DNA Sequencing Core Facility of the Institute of Biomedical Sciences of Academia Sinica for providing DNA sequencing services. We also thank the Plant Technology Core Facility of Academia Sinica for assistance in BiFC experiments, Shu-Chen Shen at the Confocal Microscope Core facility for her assistance in microscopy, and Miranda Loney for English editing. This work was supported by the Innovative Translational Agricultural Research Program to S.S. Ko (iTAR 104-2313-B-001-003).

Conflicts of Interest: The authors declare no conflict of interest. 


\section{Abbreviations}

$\begin{array}{ll}\text { AB } & \text { Axillary bud } \\ \text { BiFC } & \text { Bimolecular florescence complementation } \\ \text { FT } & \text { FLOWERING LOCUS T } \\ \text { Phal. } & \text { Phalaenopsis aphrodite } \\ \text { SPK1 } & \text { Spike Activator 1 } \\ \text { RT-qPCR } & \text { Quantitative real-time polymerase chain reaction } \\ \text { VIGS } & \text { Virus-induced gene silencing } \\ \text { Y2H } & \text { Yeast two hybrid }\end{array}$

\section{References}

1. Lee, N.; Lin, G.M. Effect of temperature on growth and flowering of Phalaenopsis white hybrid. J. Chin. Soc. Hort. Sci. 1984, 30, 223-231.

2. Blanchard, M.G.; Runkle, E.S. Temperature during the day, but not during the night, controls flowering of Phalaenopsis orchids J. Exp. Bot. 2006, 57, 4043-4049. [CrossRef] [PubMed]

3. Chen, W.H.; Tseng, Y.C.; Liu, Y.C.; Chuo, C.M.; Chen, P.T.; Tseng, K.M.; Yeh, Y.C.; Ger, M.J.; Wang, H.L. Cool-night temperature induces spike emergence and affects photosynthetic efficiency and metabolizable carbohydrate and organic acid pools in Phalaenopsis aphrodite. Plant Cell Rep. 2008, 27, 1667-1675. [CrossRef] [PubMed]

4. Newton, L.A.; Runkle, E.S. High-temperature inhibition of flowering of Phalaenopsis and Doritaenopsis orchids. Hortscience 2009, 44, 1271-1276. [CrossRef]

5. Liu, Y.C.; Liu, C.H.; Lin, Y.C.; Lu, C.H.; Chen, W.H.; Wang, H.L. Effect of low irradiance on the photosynthetic performance and spiking of Phalaenopsis. Photosynthetica 2016, 54, 259-266. [CrossRef]

6. Sakanishi, Y.; Imanishi, H.; Ishida, G. Effect of temperature on growth and flowering of Phalaenopsis amabilis. Bull. Uni. Osaka Prefect. Series B: Agri. Biol. 1980, 32, 1-9.

7. Abe, M.; Kobayashi, Y.; Yamamoto, S.; Daimon, Y.; Yamaguchi, A.; Ikeda, Y.; Ichinoki, H.; Notaguchi, M.; Goto, K.; Araki, T. FD, a bZIP protein mediating signals from the floral pathway integrator FT at the shoot apex. Science 2005, 309, 1052-1056. [CrossRef]

8. Jang, S.; Choi, S.C.; Li, H.Y.; An, G.; Schmelzer, E. Functional characterization of Phalaenopsis aphrodite flowering genes PaFT1 and PaFD. PLoS ONE 2015, 10, e0134987. [CrossRef]

9. Corbesier, L.; Vincent, C.; Jang, S.; Fornara, F.; Fan, Q.; Searle, I.; Giakountis, A.; Farrona, S.; Gissot, L.; Turnbull, C.; et al. FT protein movement contributes to long-distance signaling in floral induction of Arabidopsis. Science 2007, 316, 1030-1033. [CrossRef]

10. Lin, H.Y.; Chen, J.C.; Wei, M.J.; Lien, Y.C.; Li, H.H.; Ko, S.S.; Liu, Z.H.; Fang, S.C. Genome-wide annotation, expression profiling, and protein interaction studies of the core cell-cycle genes in Phalaenopsis aphrodite. Plant Mol. Biol. 2014, 84, 203-226. [CrossRef]

11. Inze, D.; De Veylder, L. Cell cycle regulation in plant development. Annu. Rev. Genet. 2006, 40, 77-105. [CrossRef] [PubMed]

12. Chen, T.K.; Yang, H.T.; Fang, S.C.; Lien, Y.C.; Yang, T.T.; Ko, S.S. Hybrid-Cut: An improved sectioning method for recalcitrant plant tissue samples. J. Vis. Exp. 2016, 117, e54754. [CrossRef] [PubMed]

13. Vergara, R.; Noriega, X.; Parada, F.; Dantas, D.; Perez, F.J. Relationship between endodormancy, FLOWERING LOCUS T and cell cycle genes in Vitis vinifera. Planta 2015. [CrossRef] [PubMed]

14. Cosgrove, D.J. Plant expansins: Diversity and interactions with plant cell walls. Curr. Opin. Plant Biol. 2015, 25, 162-172. [CrossRef]

15. Cosgrove, D.J. New genes and new biological roles for expansins. Curr. Opin. Plant Biol. 2000, 3, 73-78. [CrossRef]

16. Cosgrove, D.J. Loosening of plant cell walls by expansins. Nature 2000, 407, 321-326. [CrossRef]

17. Feller, A.; Machemer, K.; Braun, E.L.; Grotewold, E. Evolutionary and comparative analysis of MYB and bHLH plant transcription factors. Plant J. 2011, 66, 94-116. [CrossRef]

18. Liu, H.; Yu, X.; Li, K.; Klejnot, J.; Yang, H.; Lisiero, D.; Lin, C. Photoexcited CRY2 interacts with CIB1 to regulate transcription and floral initiation in Arabidopsis. Science 2008, 322, 1535-1539. [CrossRef] 
19. Fursova, O.V.; Pogorelko, G.V.; Tarasov, V.A. Identification of ICE2, a gene involved in cold acclimation which determines freezing tolerance in Arabidopsis thaliana. Gene 2009, 429, 98-103. [CrossRef]

20. Chinnusamy, V.; Ohta, M.; Kanrar, S.; Lee, B.H.; Hong, X.; Agarwal, M.; Zhu, J.K. ICE1: A regulator of cold-induced transcriptome and freezing tolerance in Arabidopsis. Genes Dev. 2003, 17, 1043-1054. [CrossRef]

21. Lee, S.; Lee, S.; Yang, K.Y.; Kim, Y.M.; Park, S.Y.; Kim, S.Y.; Soh, M.S. Overexpression of PRE1 and its homologous genes activates Gibberellin-dependent responses in Arabidopsis thaliana. Plant Cell Physiol. 2006, 47, 591-600. [CrossRef] [PubMed]

22. Ni, M.; Tepperman, J.M.; Quail, P.H. PIF3, a phytochrome-interacting factor necessary for normal photoinduced signal transduction, is a novel basic helix-loop-helix protein. Cell 1998, 95, 657-667. [CrossRef]

23. Bernhardt, C.; Lee, M.M.; Gonzalez, A.; Zhang, F.; Lloyd, A.; Schiefelbein, J. The bHLH genes GLABRA3 (GL3) and ENHANCER OF GLABRA3 (EGL3) specify epidermal cell fate in the Arabidopsis root. Development 2003, 130, 6431-6439. [CrossRef] [PubMed]

24. Friedrichsen, D.M.; Nemhauser, J.; Muramitsu, T.; Maloof, J.N.; Alonso, J.; Ecker, J.R.; Furuya, M.; Chory, J. Three redundant brassinosteroid early response genes encode putative bHLH transcription factors required for normal growth. Genetics 2002, 162, 1445-1456. [PubMed]

25. Ohashi-Ito, K.; Bergmann, D.C. Arabidopsis FAMA controls the final proliferation/differentiation switch during stomatal development. Plant Cell 2006, 18, 2493-2505. [CrossRef]

26. Heisler, M.G.; Atkinson, A.; Bylstra, Y.H.; Walsh, R.; Smyth, D.R. SPATULA, a gene that controls development of carpel margin tissues in Arabidopsis, encodes a bHLH protein. Development 2001, 128, 1089-1098.

27. Oikawa, T.; Kyozuka, J. Two-step regulation of LAX PANICLE1 protein accumulation in axillary meristem formation in rice. Plant Cell 2009, 21, 1095-1108. [CrossRef]

28. Ohashi-Ito, K.; Saegusa, M.; Iwamoto, K.; Oda, Y.; Katayama, H.; Kojima, M.; Sakakibara, H.; Fukuda, H. A bHLH complex activates vascular cell division via cytokinin action in root apical meristem. Curr. Biol. 2014, 24, 2053-2058. [CrossRef]

29. Su, C.L.; Chao, Y.T.; Yen, S.H.; Chen, C.Y.; Chen, W.C.; Chang, Y.C.; Shih, M.C. Orchidstra: An integrated orchid functional genomics database. Plant Cell Physiol. 2013, 54, e11. [CrossRef]

30. Lu, H.C.; Chen, H.H.; Tsai, W.C.; Chen, W.H.; Su, H.J.; Chang, D.C.; Yeh, H.H. Strategies for functional validation of genes involved in reproductive stages of orchids. Plant Physiol. 2007, 143, 558-569. [CrossRef]

31. Sheldon, C.C.; Finnegan, E.J.; Rouse, D.T.; Tadege, M.; Bagnall, D.J.; Helliwell, C.A.; Peacock, W.J.; Dennis, E.S. The control of flowering by vernalization. Curr. Opin. Plant Biol. 2000, 3, 418-422. [CrossRef]

32. Haywood, V.; Yu, T.S.; Huang, N.C.; Lucas, W.J. Phloem long-distance trafficking of GIBBERELLIC ACID-INSENSITIVE RNA regulates leaf development. Plant. J. 2005, 42, 49-68. [CrossRef] [PubMed]

33. Hanano, S.; Goto, K. Arabidopsis TERMINAL FLOWER1 is involved in the regulation of flowering time and inflorescence development through transcriptional repression. Plant. Cell 2011, 23, 3172-3184. [CrossRef] [PubMed]

34. Saitou, N.; Nei, M. The neighbor-joining method: A new method for reconstructing phylogenetic trees. Mol. Biol. Evol. 1987, 4, 406-425. [CrossRef]

35. Kumar, S.; Stecher, G.; Li, M.; Knyaz, C.; Tamura, K. MEGA X: Molecular Evolutionary Genetics Analysis across Computing Platforms. Mol. Biol. Evol. 2018, 35, 1547-1549. [CrossRef]

36. Zuckerkandl, E.; Pauling, L. Evolutionary Divergence and Convergence in Proteins; Academic Press: New York, NY, USA, 1965.

37. Lin, Y.J.; Chen, Y.C.; Tseng, K.C.; Chang, W.C.; Ko, S.S. Phototropins Mediate Chloroplast Movement in Phalaenopsis aphrodite (Moth Orchid). Plant. Cell Physiol. 2019, 60, 2243-2254. [CrossRef]

38. Hsu, C.T.; Liao, D.C.; Wu, F.H.; Liu, N.T.; Shen, S.C.; Chou, S.J.; Tung, S.Y.; Yang, C.H.; Chan, M.T.; Lin, C.S. Integration of molecular biology tools for identifying promoters and genes abundantly expressed in flowers of Oncidium Gower Ramsey. BMC Plant. Biol. 2011, 11, 60. [CrossRef]

39. Ko, S.S.; Li, M.J.; Ku, M.S.-B.; Ho, Y.C.; Lin, Y.J.; Chuang, M.H.; Hsing, H.X.; Lien, Y.C.; Yang, H.T.; Chang, H.C.; et al. The bHLH142 transcription factor coordinates with TDR1 to modulate the expression of EAT1 and regulate pollen development in rice. Plant. Cell 2014, 26, 2486-2504. [CrossRef]

(C) 2019 by the authors. Licensee MDPI, Basel, Switzerland. This article is an open access article distributed under the terms and conditions of the Creative Commons Attribution (CC BY) license (http://creativecommons.org/licenses/by/4.0/). 